\title{
Analisis Kualitas Produk Velg Rubber Roll Dengan Metode Six Sigma Dan Kaizen Di PT.XYZ, Klaten
}

\author{
Al Basith ${ }^{1}$, Masrul Indrayana ${ }^{2}$, Jono ${ }^{3}$ \\ ${ }^{1,2,3)}$ Fakultas Sain danTeknologi, Program Studi Teknik Industri, Universitas Widya Mataram \\ Dalem Mangkubumen KT.III/237 Yogyakarta \\ Email: basittrueblues@gmail.com, masrul_indrayana@yahoo.com, kartajono92@gmail.com
}

\begin{abstract}
ABSTRAK
PT.Mitra Rekatama Mandiri adalah perusahaan yang bergerak dalam bidang pengecoran logam, non logam dan permesinan dengan hasil produksi berupa komponen pertambangan, komponen alat pertanian, dan komponen konstruksi. Dalam proses produksinya sering kali produk yang dihasilkan tidak dapat mencapai standar kualitas yang ditentukan oleh perusahaan. Salah satu produk yang dihasilkan adalah velg rubber roll. Dari pengamatan awal diketahui masih terdapat cacat produk sebesar 3\% dari produk yang dihasilkan. Sehingga produksi velg rubber roll oleh PT.XYZ perlu dilakukan perbaikan kualitas agar mencapai zero defect atau tanpa cacat. Untuk mencapai produk tanpa cacat dapat melalui kajian menggunakan metode Six Sigma DMAIC dan Kaizen. Metode DMAIC digunakan untuk menganalisa faktor penyebab cacat. Sementara metode kaizen digunakan untuk mengupayakan perbaikan berkesinambungan. Hasil Penelitian menunjukkan Jenis cacat paling banyak terjadi yaitu, cacat mengsle. Faktor dominan penyebab cacat adalah keliru dalam pembuatan pola dan cetakan.Usulan perbaikan yang diberikan kepada pihak perusahaan yaitu: Melakukan pelatihan kerja bagi para operator, melakukan penilaian kinerja dan melakukan pengawasan pada setiap aktivitas kerja operator.
\end{abstract}

Kata kunci: kualitas produk ,zero defect, six sigma, kaizen, pelatihan kerja

\begin{abstract}
PT. XYZ is a company engaged in the casting of metals, non-metals and machinery with production results in the form of mining components, agricultural equipment components, and construction components. In the production process often the products produced cannot reach the quality standards set by the company. One of the products produced is rubber roll wheels. From initial observations it was known that there are still 3\% product defects of the products manufactured. It means that PT. XYZ needs to improve the rubber roll wheels quality in order to achieve zero defects or without defects. To achieve the product without defects can be done through a study using the Six Sigma DMAIC and Kaizen methods. The DMAIC method is used to analyze the causes of defects. While the kaizen method is used to strive for continuous improvement. esearch results show. The dominant factor causing defects is mistaken in making patterns and prints. Proposed improvements given to the company is: To conduct work training for operators, conduct performance appraisal and conduct supervision on each operator's work activities.
\end{abstract}

Keywords: Product Quality, ,zero defect, Six Sigma, Kaizen, work training

\section{PENDAHULUAN}

Perkembangan industri di era modern ini sangat pesat sekali. Perkembangan ini harus diiringi dengan tuntutan konsumen mengenai kualitas produk. Perusahaan yang memproduksi produk dengan kualitas rendah pasti pasarnya akan menurun. Hal ini terjadi karena produknya tidak bisa merebut hati konsumen. Mengakibatkan volume penjualan rendah, sehingga profit perusahaan menurun. Di pasar, biasanya konsumen akan menggunakan produk yang memberikan kepuasan sesuai kebutuhannya. Sehingga menjaga loyalitas konsumen menjadi wajib dipertahankan jika menginginkan produknya tetap eksis dipasaran. Untuk itu jika perusahaan ingin produknya laris di pasaran, maka harus mempertahankan kualitasnya.

Kualitas merupakan keseluruhan karakteristik dan keistimewaan dari suatu produk atau jasa yang dihasilkan dari kemampuan produk atau jasa untuk memuaskan sebagian atau secara keseluruhan kebutuhan dari konsumen. Konsumen sebagai pemakai produk semakin kritis dalam memilih produk yang akan dipakai, 
sehingga mengakibatkan peranan kualitas semakin penting. Berbagai macam metode dikembangkan guna menjamin kualitas dalam sebuah proses produksi salah satunya zero defect atau tanpa cacat.

PT. XYZ adalah perusahaan yang bergerak dalam bidang industri manufaktur pengecoran logam, non logam dan permesinan. Produk utama PT XYZ yaitu komponen pertambangan, komponen alat pertanian, komponen konstruksi dan komponen produk lain. Dalam proses produksinya sering kali tidak semua produk yang dihasilkan dapat mencapai standar kualitas yang telah ditentukan oleh perusahaan. Hal ini menunjukan adanya produk cacat, disebabkan karena seringnya terjadi kesalahan-kesalahan baik faktor mesin atau sumber daya manusia dll.

Salah satu produk yang paling sering diproduksi oleh PT. XYZ adalah Velg Rubber Roll. Velg Rubber Roll merupakan salah satu komponen yang digunakan pada mesin penggiling padi. Kualitas produk ini harus selalu dijaga untuk memenuhi keinginan konsumen. Dari pengamatan awal diketahui masih banyak terjadi cacat dalam produk ini. Hasil pengamatan nilai kecacatan sebesar 3 persen dari produk yang dihasilkan, sehingga produksi Velg Rubber Roll oleh PT. XYZ perlu dilakukan perbaikan.

Berdasarkan latar belakang tersebut maka perlunya dilakukan penelitian dengan menggunakan metode DMAIC dan Kaizen. Metode DMAIC digunakan untuk mengukur tingkat kapabilitas proses, mengetahui jenis-jenis cacat yang terjadi, serta digunakan untuk menganalisis factor-faktor dominan penyebab kecacatan pada produk velg rubber roll. Metode ini disusun berdasarkan sebuah metodologi penyelesaian yang sederhana, dimana didalam metode six sigma ini terdapat penyelesaian masalah yaitu: define (merumuskan), measure (mengukur), analyze (menganalisa), improve (meningkatkan/memperbaiki), dan control (mengendalikan) yang menggabungkan bermacam-macam perangkat statistik serta pendekatan perbaikan proses lainya. Sedangkan metode kaizen ialah metode yang digunakan untuk mengupayakan perbaikan secara berkesinambungan yang berarti tindakan terus menerus yang meliputi setiap orang, termasuk manajer maupun pekerja, perbaikan tersebut meliputi pemeliharaan dan penyempurnaan. Tindakan pengawasan meliputi penetapan kebijakan, petujuk peraturan, SOP (standar operasional prosedur) dan pengawasan, sedangkan tindakan perawatan diantaranya adalah training-training yang dilakukan sebagai penambah wawasan.

\section{METODE PENELITIAN}

Penelitian dilakukan di PT.Mtra Rekatama Mandiri, yang beralamatkan di Jalan. Koperasi Baja No.02, Ngowo, Ceper, Klaten, Jawa Tengah. Dengan produk yang diteliti berupa Velg Rubber Roll yang merupakan salah satu elemen untuk mesin penggiling padi. Data yang digunakan dalam penelitian ini adalah: Data jumlah hasil produksi per-minggu velg rubber roll selama periode penelitian bulan Januari sampai dengan bulan April 2019, data jenis-jenis cacat velg rubber roll dan data jumlah produk cacat pada velg rubber roll. Pengambilan data dilakukan setiap hari kerja selama empat bulan (dimulai dari bulan Januari tanggal 2 sampai 30 April 2019) pada proses produksi velg rubber roll dan data dikelompokkan menjadi per-minggu sesuai dengan jenis cacatnya. Tahapan penelitian ini mengacu pada Tannady [1] dan Gasperz [2] untuk menyelesaikan masalah dan peningkatan proses melalui tahap DMAIC (Define, Measure, Analyze, Improve, Control).

1) Define (Defenisi) langkah yang akan dilakukan adalah sebagai berikut:

a. Proses Mapping

Tahap ini akan menyajikan urutan proses produksi.

2) Measure (Pengukuran)

Langkah kedua adalah pengukuran (measure) yang akan menyajikan beberapa tahap berikut:

a. Penetapan CTQ (Critical to Quality).

b. Mengetahui Urutan CTQ (Critical to Quality) menggunakan diagram pareto.

c. Pengukuran Stabilitas Proses (Proporsi, CL, UCL,LCL dan grafik peta kontrol p), Wahyuni dkk [3].

d. Pengukuran Kapabilitas Proses untuk mengetahui nilai DPMO dan nilai sigma [4].

3) Analyze (Analisa)

a. Mengetahui Penyebab Terjadinya Cacat menggunakan FMEA. Kemudian dilakukan perhitungan RPN (Risk Potential Number) untuk menentukan faktor dominan yang sering terjadi dalam proses produksi.

b. Penelusuran Akar Penyebab Masalah menggunakan diagram fishbone melalui pandangan lima faktor yaitu manusia, metode, mesin, material, lingkungan [5]

4) Improvement dan Control

Pada tahap ini akan menyajikan usulan perbaikan dan pengendalian yang didapat dari intrepretasi hasil. Dalam upaya memberikan usulan perbaikan, akan dilakukan melalui konsep bertanya 5W-1H yaitu What (apa), Why (mengapa), Where (dimana), When (kapan atau bilamana), Who (siapa) dan How (bagaimana). Selanjutnya menetapkan kaizen sebagai saran untuk perbaikan menggunakan Kaizen FiveStep Plan dan Kaizen Five M Cheklist [6]. 


\section{HASIL DAN PEMBAHASAN}

\section{Tahap Define}

Tahap ini digunakan untuk melakukan identifikasi terhadap permasalahan-permasalahan yang terjadi melalui proses pemetaan (mapping).

Tabel 1. Rekaman Aktivitas Process Aktivity Mapping

\begin{tabular}{|c|c|c|c|c|c|c|c|c|c|c|c|}
\hline \multirow[b]{2}{*}{ No. } & \multirow[b]{2}{*}{ Aktivitas } & \multirow{2}{*}{$\begin{array}{l}\text { Mesin / } \\
\text { Alat }\end{array}$} & \multirow{2}{*}{$\begin{array}{c}\text { Jarak } \\
(\mathrm{m})\end{array}$} & \multirow{2}{*}{$\begin{array}{l}\text { Waktu } \\
\text { (detik) }\end{array}$} & \multirow{2}{*}{$\begin{array}{l}\text { Jml } \\
\text { TK }\end{array}$} & \multicolumn{5}{|c|}{ Aktivitas } & \multirow{2}{*}{$\begin{array}{c}\mathrm{VA} / \\
\mathrm{NVA} / \\
\mathrm{NNV} \\
\mathrm{A}\end{array}$} \\
\hline & & & & & & $\mathrm{O}$ & $\mathrm{T}$ & $\mathrm{I}$ & $\mathrm{S}$ & $\mathrm{D}$ & \\
\hline 1. & Menggali pasir untuk membuat cetakan & $\begin{array}{c}\text { Cangku } \\
1\end{array}$ & - & 21,32 & 1 & 1 & & & & & VA \\
\hline 2. & Pola produk dipendam dalam pasir & - & - & 6,74 & 1 & 1 & & & & & VA \\
\hline 3. & Pola cetakan ditutup pasir & - & - & 18,19 & 1 & 1 & & & & & VA \\
\hline 4. & Pasir dipadatkan & $\begin{array}{c}\text { Penumb } \\
\text { uk }\end{array}$ & - & 29,96 & 1 & 1 & & & & & VA \\
\hline 5. & Permukaan pola produk dirapikan & - & - & 68,29 & 1 & & & 1 & & & $\begin{array}{c}\mathrm{NNV} \\
\mathrm{A}\end{array}$ \\
\hline 6. & $\begin{array}{l}\text { Pemasangan rangka cetakan diatas pola } \\
\text { produk }\end{array}$ & - & - & 7,04 & 1 & 1 & & & & & VA \\
\hline 7. & Pemasangangan pipa ujung kanan atas & - & - & 4,05 & 1 & 1 & & & & & VA \\
\hline 8. & Penimbunan pasir & $\begin{array}{c}\text { Cangku } \\
1\end{array}$ & - & 46,97 & 1 & 1 & & & & & VA \\
\hline 9. & Pasir dipadatkan dengan penumbuk & $\begin{array}{c}\text { Penumb } \\
\text { uk }\end{array}$ & - & 71,49 & 1 & 1 & & & & & VA \\
\hline 10. & Pelepasan pipa & - & - & 3,94 & 1 & 1 & & & & & VA \\
\hline 11. & Rangka cetakan persegi diangkat & - & - & 2,88 & 1 & 1 & & & & & VA \\
\hline 12. & $\begin{array}{lllll}\begin{array}{l}\text { Permukaan } \\
\text { secukupnya }\end{array} & \text { pola produk diberi air } \\
\end{array}$ & - & - & 22,99 & 1 & 1 & & & & & VA \\
\hline 13. & $\begin{array}{l}\text { Pembuatan saluran untuk masuknya caira } \\
\text { logam }\end{array}$ & Manual & - & 24,01 & 1 & 1 & & & & & VA \\
\hline 14. & $\begin{array}{l}\text { Pola produk dipukul untuk memudahkan } \\
\text { proses pengambilan }\end{array}$ & $\begin{array}{c}\text { Balok } \\
\text { kayu }\end{array}$ & - & 7,02 & 1 & 1 & & & & & $\begin{array}{c}\mathrm{NNV} \\
\mathrm{A}\end{array}$ \\
\hline 15. & $\begin{array}{l}\text { Pola produk diangkat sehingga terbentuk } \\
\text { pola produk pada alas cetakan pasir }\end{array}$ & $\begin{array}{c}\text { Pencun } \\
\text { gkil }\end{array}$ & - & 16,30 & 1 & 1 & & & & & VA \\
\hline 16. & $\begin{array}{llll}\begin{array}{l}\text { Alas cetakan } \\
\text { dirapikan }\end{array} & \text { pasir yang terbentuk } \\
\end{array}$ & Manual & - & 36,01 & 1 & 1 & & & & & $\begin{array}{c}\text { NNV } \\
\text { A }\end{array}$ \\
\hline 17. & Rangka cetakan persegi ditutup kembali & - & - & 11,98 & 1 & 1 & & & & & VA \\
\hline 18. & $\begin{array}{l}\text { Rangka cetakan persegi dilepas sehingga } \\
\text { terbentuk cetakan pasir }\end{array}$ & - & - & 5,17 & 1 & 1 & & & & & VA \\
\hline 19 & Set up mesin tungku peleburan & - & - & 4200,0 & 2 & & & 1 & & & $\begin{array}{c}\mathrm{NNV} \\
\mathrm{A}\end{array}$ \\
\hline 20 & Melakukan timbangan bahan baku logam & $\begin{array}{c}\text { Timban } \\
\text { gan }\end{array}$ & - & 32,96 & 2 & & & 1 & & & $\begin{array}{c}\mathrm{NNV} \\
\mathrm{A}\end{array}$ \\
\hline 21 & $\begin{array}{l}\text { Masukan geram kedalam tungku hingga } \\
\text { hampir memenuhi kapasitas tungku }\end{array}$ & Sekop & - & 23,00 & 1 & 1 & & & & & VA \\
\hline 22 & $\begin{array}{l}\text { Bahan baku diaduk sampai berwarna } \\
\text { merah }\end{array}$ & $\begin{array}{c}\text { Pengad } \\
\text { uk }\end{array}$ & - & 300,27 & 1 & 1 & & & & & VA \\
\hline
\end{tabular}


Tabel 1. Rekaman Aktivitas Process Aktivity Mapping (lanjutan)

\begin{tabular}{|c|c|c|c|c|c|c|c|c|c|c|c|}
\hline \multirow{2}{*}{ No. } & \multirow{2}{*}{ Aktivitas } & \multirow{2}{*}{$\begin{array}{c}\text { Mesin / } \\
\text { Alat }\end{array}$} & \multirow{2}{*}{$\begin{array}{c}\text { Jarak } \\
(\mathrm{m})\end{array}$} & \multirow{2}{*}{$\begin{array}{l}\text { Waktu } \\
\text { (detik) }\end{array}$} & \multirow{2}{*}{$\begin{array}{l}\text { Jml } \\
\text { TK }\end{array}$} & \multicolumn{5}{|c|}{ Aktivitas } & \multirow{2}{*}{$\begin{array}{l}\text { VA/ } \\
\text { NVA/ } \\
\text { NNVA }\end{array}$} \\
\hline & & & & & & $\mathrm{O}$ & $\mathrm{T}$ & I & $S$ & $\mathrm{D}$ & \\
\hline 23 & $\begin{array}{l}\text { Masukan silikon kedalam tungku } \\
\text { peleburan }\end{array}$ & Sekop & - & 37,63 & 1 & 1 & & & & & VA \\
\hline 24 & $\begin{array}{l}\text { Mengaduk bahan baku logam sampai } \\
\text { melebur hingga siap untuk } \\
\text { dituangkan ke ladel besar }\end{array}$ & $\begin{array}{l}\text { Pengadu } \\
\mathrm{k}\end{array}$ & - & 7200,0 & 1 & 1 & & & & & VA \\
\hline 25 & $\begin{array}{l}\text { Melapisi ladel kecil dengan pasir } \\
\text { yang telah dicampur tanah liat dan } \\
\text { air }\end{array}$ & - & - & 210,56 & 1 & 1 & & & & & VA \\
\hline 26 & $\begin{array}{l}\text { Penuangan cairan logam panas dari } \\
\text { tungku ke ladel besar }\end{array}$ & - & - & 215,57 & 1 & 1 & & & & & VA \\
\hline 27 & $\begin{array}{l}\text { Ladel ditarik ditarik melewati jalur } \\
\text { yang telah ditentukan }\end{array}$ & - & - & 20,72 & 2 & 1 & & & & & NNVA \\
\hline 28 & $\begin{array}{l}\text { Menuangkan cairan logam panas dari } \\
\text { ladel besar ke dalam ladel kecil }\end{array}$ & $\begin{array}{l}\text { Ladel } \\
\text { kecil }\end{array}$ & - & 6,53 & 2 & 1 & & & & & VA \\
\hline 29 & $\begin{array}{l}\text { Menuangkan cairan logam kedalam } \\
\text { masing-masing cetakan pasir }\end{array}$ & $\begin{array}{l}\text { Ladel } \\
\text { kecil }\end{array}$ & - & 25,76 & 1 & 1 & & & & & VA \\
\hline 30 & $\begin{array}{l}\text { Cairan logam panas dalam cetakan } \\
\text { pasir didiamkan }\end{array}$ & - & - & 1020,0 & - & & & 1 & & & NNVA \\
\hline 31 & Menungggu produk dibongkar & - & - & 438,00 & - & & & & & 1 & NVA \\
\hline 32 & Mengambil alat pencungkil cetakan & - & - & 1,63 & 1 & & 1 & & & & NNVA \\
\hline 33 & $\begin{array}{l}\text { Mencungkil produk dalam cetakan } \\
\text { pasir dengan alat bantu }\end{array}$ & $\begin{array}{l}\text { Pencung } \\
\text { kil }\end{array}$ & - & 2,89 & 1 & 1 & & & & & VA \\
\hline 34 & $\begin{array}{l}\text { Mendiamkan produk untuk } \\
\text { menurunkan suhunya }\end{array}$ & - & - & 600,00 & - & & & 1 & & & NNVA \\
\hline 35 & $\begin{array}{l}\text { Menunggu untuk diangkut ke tempat } \\
\text { pembubutan }\end{array}$ & - & - & 1380,0 & - & & & & & 1 & NVA \\
\hline 36 & Setting mata pisau mesin bubut & Kunci T & - & 10,76 & 1 & & & & & 1 & NVA \\
\hline 37 & Mengambil produk per-unit & - & - & 5,75 & 1 & 1 & & & & & VA \\
\hline 38 & $\begin{array}{l}\text { Pemasangan produk pada chuck } \\
\text { (pencengkraman mesin bubut) }\end{array}$ & - & - & 7,57 & 1 & 1 & & & & & VA \\
\hline 39 & Menyalakan mesin bubut & - & - & 1,76 & 1 & 1 & & & & & VA \\
\hline 40 & $\begin{array}{l}\text { Proses pembubutan produk sesuai } \\
\text { kriteria }\end{array}$ & $\begin{array}{l}\text { Mesin } \\
\text { gerinda }\end{array}$ & - & 680,00 & 1 & 1 & & & & & VA \\
\hline 41 & Mematikan mesin bubut & - & - & 1,75 & 1 & 1 & & & & & VA \\
\hline 42 & Mengambil produk dari mesin bubut & - & - & 5,92 & 1 & & 1 & & & & NNVA \\
\hline 43 & $\begin{array}{l}\text { Memindahkan produk kebagian } \\
\text { penghalusan }\end{array}$ & Manual & 20 & 40,52 & 4 & & 1 & & & & NNVA \\
\hline 44 & $\begin{array}{l}\text { Mesin gerinda di setting sesuai } \\
\text { dengan kebutuhan produk }\end{array}$ & - & - & 8,23 & 1 & 1 & & & & & VA \\
\hline
\end{tabular}


Tabel 1. Rekaman Aktivitas Process Aktivity Mapping (lanjutan)

\begin{tabular}{|c|c|c|c|c|c|c|c|c|c|c|c|}
\hline \multirow[b]{2}{*}{ No. } & \multirow[b]{2}{*}{ Aktivitas } & \multirow{2}{*}{$\begin{array}{c}\text { Mesin / } \\
\text { Alat }\end{array}$} & \multirow{2}{*}{$\begin{array}{c}\text { Jarak } \\
(\mathrm{m})\end{array}$} & \multirow{2}{*}{$\begin{array}{l}\text { Waktu } \\
\text { (detik) }\end{array}$} & \multirow{2}{*}{$\begin{array}{l}\text { Jml } \\
\text { TK }\end{array}$} & \multicolumn{5}{|c|}{ Aktivitas } & \multirow{2}{*}{$\begin{array}{c}\text { VA/ } \\
\text { NVA/ } \\
\text { NNVA }\end{array}$} \\
\hline & & & & & & $\mathrm{O}$ & $\mathrm{T}$ & I & $S$ & $\mathrm{D}$ & \\
\hline 45 & Menyalakan mesin gerinda & - & - & 1,52 & 1 & 1 & & & & & VA \\
\hline 46 & $\begin{array}{l}\text { Produk dihaluskan pada keseluruhan } \\
\text { bagiannya }\end{array}$ & Gerinda & - & 420,0 & 1 & 1 & & & & & VA \\
\hline 47 & Mematikan mesin gerinda & - & - & 1,45 & 1 & 1 & & & & & VA \\
\hline 48 & Memindahkan produk ke gudang & $\begin{array}{c}\text { Gerobak/ } \\
\text { manual }\end{array}$ & 11 & 13,22 & 1 & & 1 & & & & NNVA \\
\hline \multicolumn{4}{|c|}{ Total } & $\begin{array}{l}17318 \\
32\end{array}$ & & $\begin{array}{l}3 \\
6\end{array}$ & 4 & 5 & 0 & 3 & \\
\hline
\end{tabular}

Pengelompokkan waktu aktivitas sesuai dengan tipe aktivitasnya bertujuan untuk mengetahui persentase dari setiap tipe aktivitas dalam keseluruhan proses produksi velg rubber roll. Tabel waktu pada setiap jenis aktivitas disajikan pada Tabel 2 berikut.

Tabel 2. Tipe Aktivitas

\begin{tabular}{|c|l|c|c|c|c|}
\hline \multirow{2}{*}{ No. } & \multirow{2}{*}{ Tipe Aktivitas } & \multicolumn{2}{|c|}{ Aktivitas } & \multicolumn{2}{c|}{ Waktu } \\
\cline { 3 - 5 } & & Jumlah & Persentase & $\begin{array}{c}\text { Jumlah } \\
\text { (Detik) }\end{array}$ & $\begin{array}{c}\text { Total } \\
\text { Persentase }\end{array}$ \\
\hline 1 & Operasi (O) & 36 & $75,00 \%$ & 9507,02 & $54,88 \%$ \\
\hline 2 & Transportasi (T) & 4 & $8,33 \%$ & 61,29 & $3,35 \%$ \\
\hline 3 & Inspeksi (I) & 5 & $10,42 \%$ & 5927 & $34,21 \%$ \\
\hline 4 & Store (S) & 0 & $0 \%$ & 0 & $0 \%$ \\
\hline 5 & Delay (D) & 3 & $6,25 \%$ & 1828,76 & $10,56 \%$ \\
\hline & Jumlah & 48 & $100 \%$ & & $100 \%$ \\
\hline
\end{tabular}

Pengelompokkan jumlah aktivitas sesuai dengan jenis kategorinya bertujuan untuk mengetahui persentase dari setiap kategori dalam keseluruhan aktivitas proses produksi velg rubber roll. Tabel jumlah aktivitas dan waktu tiap kategori disajikan pada Tabel 3 berikut.

Tabel 3. Kategori Aktivitas

\begin{tabular}{|c|l|c|c|c|c|}
\hline \multirow{2}{*}{ No. Kategori } & \multicolumn{2}{c|}{ Aktivitas } & \multicolumn{2}{c|}{ Waktu } \\
\cline { 3 - 6 } & & Jumlah & Persentase & $\begin{array}{c}\text { Jumlah } \\
\text { (Detik) }\end{array}$ & $\begin{array}{c}\text { Total } \\
\text { Persentase }\end{array}$ \\
\hline 1 & Value Added (VA) & 34 & $70,83 \%$ & 9463,99 & $54,58 \%$ \\
\hline 2 & Non Value Added (NVA) & 3 & $6,25 \%$ & 1828,76 & $10,55 \%$ \\
\hline 3 & Necessary Non Value Added (NNVA) & 11 & $22,92 \%$ & 6046,29 & $34,87 \%$ \\
\hline \multicolumn{2}{|c|}{ Jumlah } & 48 & $100 \%$ & & $100 \%$ \\
\hline
\end{tabular}

Dari tabel 3 dapat diketahui aktivitas VA pada proses produksi velg rubber roll diambil dari dari hasil aktivitas operasi ( dengan mengeliminasi 2 aktivitas nomor 14 dan 16) berjumlah 34 aktivitas dari 48 aktivitas atau sebesar 70,83\% dengan waktu 9463,99 detik, Aktivitas NVA diambil dari aktivitas Delay berjumlah 3 aktivitas dari 48 aktivitas atau 6,25\% dengan waktu 1828,76 detik, sedangkan aktivitas NNVA diambil dari penjumlahan transportasi, inspeksi dan 2 tipe aktivitas operasi 12 aktivitas dari 48 aktivitas atau 22,92\% dengan waktu 6046,29 detik.

\section{Tahap Measure}

Pembuatan diagram pareto untuk menentukan cacat paling dominan yang nantinya akan diidentifikasi sebagai CTQ, hasil diagram pareto seperti pada Gambar 1. 


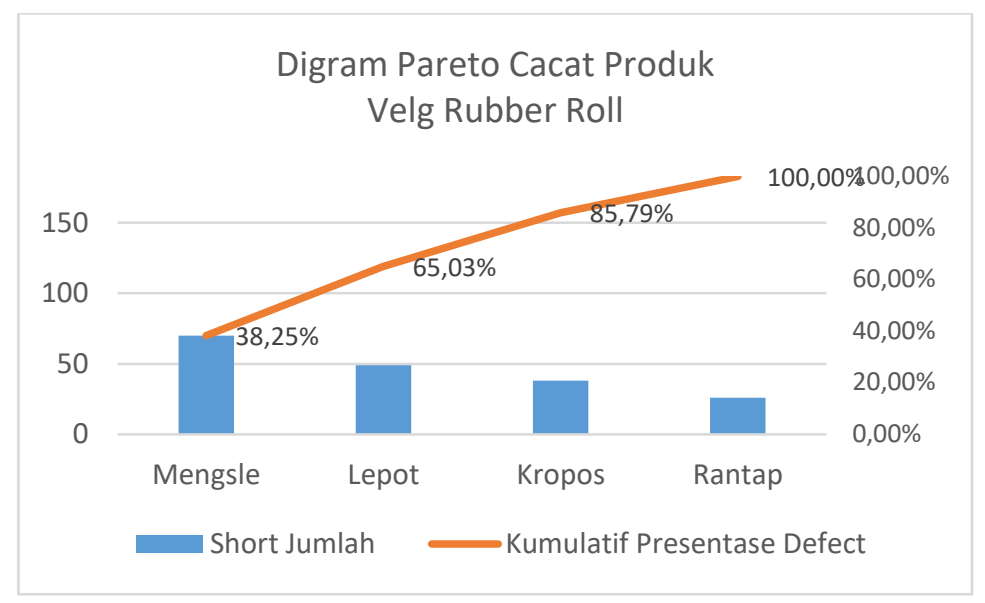

Gambar 1. Diagram Pareto

Dari hasil perhitungan diagram pareto didapatkan bahwa cacat yang dominan (yang memberikan kontribusi sampai $\pm 80 \%$ dari total jumlah cacat) dan yang dikualifikasikan sebagai CTQ dominan, sehingga harus segera dilakukan tindakan perbaikan adalah cacat mengsle, cacat lepot dan cacat kropos. Dari perhitungan didapatkan nilai DPMO sebesar 33,296 dan bila dikonversikan ke dalam nilai sigma maka nilainya adalah 3,334 .

\section{Tahap Analyze}

Pada tahap ini menentukan penyebab kegagalan proses menggunakan tabel identifikasi Failure Mode Effect Analysis (FMEA) disajikan pada tabel 4

Tabel 4. Tabel Hasil Identifikasi Penyebab Cacat Velg Rubber Roll

\begin{tabular}{|c|c|c|c|c|c|}
\hline Location & Process Name & $\begin{array}{c}\text { Potential Failure } \\
\text { Mode }\end{array}$ & $\begin{array}{c}\text { Potential } \\
\text { Effect of } \\
\text { Failure } \\
\end{array}$ & $\begin{array}{c}\text { Potential } \\
\text { Couse of } \\
\text { Failure } \\
\end{array}$ & $\begin{array}{l}\text { Current } \\
\text { Controls }\end{array}$ \\
\hline \multirow[t]{3}{*}{$\begin{array}{l}\text { Area } \\
\text { Pengecoran }\end{array}$} & \multirow[t]{3}{*}{$\begin{array}{l}\text { Pembuatan pola } \\
\text { dan } \\
\text { Cetakan } \\
\text { (molding) }\end{array}$} & $\begin{array}{l}\text { Ukuran Pola dan } \\
\text { cetakan Tidak } \\
\text { Sesuai Ukuran } \\
\text { Coran }\end{array}$ & $\begin{array}{l}\text { Cacat } \\
\text { Mengsle }\end{array}$ & $\begin{array}{l}\text { Keliru dalam } \\
\text { pembuatan } \\
\text { pola dan } \\
\text { cetakan }\end{array}$ & Inspeksi \\
\hline & & $\begin{array}{l}\text { Cetakan Pasir } \\
\text { Rontok Saat } \\
\text { Penuangan } \\
\text { Logam }\end{array}$ & $\begin{array}{l}\text { Cacat } \\
\text { Lepot }\end{array}$ & $\begin{array}{l}\text { Pasir cetakan } \\
\text { kurang padat }\end{array}$ & Inspeksi \\
\hline & & $\begin{array}{l}\text { Oksigen terjebak } \\
\text { diantara diantara } \\
\text { cairan dan pasir }\end{array}$ & $\begin{array}{l}\text { Cacat } \\
\text { Kropos }\end{array}$ & $\begin{array}{l}\text { Pasir cetakan } \\
\text { terlalu lembab }\end{array}$ & Inspeksi \\
\hline \multirow[t]{2}{*}{$\begin{array}{l}\text { Area Mesin } \\
\text { Induksi }\end{array}$} & \multirow[t]{2}{*}{ Peleburan Logam } & Cairan Muda & $\begin{array}{l}\text { Cacat } \\
\text { Lepot }\end{array}$ & $\begin{array}{l}\text { Suhu Didih Di } \\
\text { Tungku } \\
\text { Peleburan } \\
\text { Tidak } \\
\text { dilakukan } \\
\text { Pengecekan } \\
\end{array}$ & Inspeksi \\
\hline & & $\begin{array}{l}\text { Cairan Berkerak } \\
\text { Atau Ada } \\
\text { Kotoran }\end{array}$ & $\begin{array}{l}\text { Cacat } \\
\text { Kropos }\end{array}$ & $\begin{array}{l}\text { Tungku } \\
\text { Peleburan } \\
\text { Tidak } \\
\text { dilakukan } \\
\text { Pembersihan }\end{array}$ & Inspeksi \\
\hline $\begin{array}{l}\text { Area } \\
\text { Pengecoran }\end{array}$ & $\begin{array}{l}\text { Proses } \\
\text { Penuangan }\end{array}$ & $\begin{array}{l}\text { Coran tidak terisi } \\
\text { penuh }\end{array}$ & $\begin{array}{l}\text { Cacat } \\
\text { Lepot }\end{array}$ & $\begin{array}{l}\text { Tidak Cermat } \\
\text { Dalam } \\
\text { Penuangan } \\
\text { Logam }\end{array}$ & Inspeksi \\
\hline
\end{tabular}


Tabel 4. Hasil Identifikasi Penyebab Cacat Velg Rubber Roll (lanjutan)

\begin{tabular}{|l|l|l|l|l|l|}
\hline Location & Process Name & $\begin{array}{l}\text { Potential Failure } \\
\text { Mode }\end{array}$ & $\begin{array}{l}\text { Potential } \\
\text { Effect of } \\
\text { Failure }\end{array}$ & $\begin{array}{l}\text { Potential } \\
\text { Couse of } \\
\text { Failure }\end{array}$ & $\begin{array}{l}\text { Current } \\
\text { Controls }\end{array}$ \\
\hline $\begin{array}{l}\text { Area } \\
\text { Pengecoran }\end{array}$ & $\begin{array}{l}\text { Pembongkaran } \\
\text { Cetakan }\end{array}$ & $\begin{array}{l}\text { Pendinginan } \\
\text { Coran Belum } \\
\text { Sempurna }\end{array}$ & $\begin{array}{l}\text { Cacat } \\
\text { Kropos }\end{array}$ & $\begin{array}{l}\text { Pembongkaran } \\
\text { Terlalu Cepat }\end{array}$ & Inspeksi \\
\hline $\begin{array}{l}\text { Area Kerja } \\
\text { Bangku }\end{array}$ & Finishing & $\begin{array}{l}\text { Produk Tidak } \\
\text { Presisi }\end{array}$ & $\begin{array}{l}\text { Cacat } \\
\text { Mengsle }\end{array}$ & $\begin{array}{l}\text { Finishing } \\
\text { Melewati } \\
\text { Batas } \\
\text { Toleransi }\end{array}$ & Inspeksi \\
\hline
\end{tabular}

Setelah penyebab cacat produk pada proses kerja diidentifikasi maka, dapat dilakukan perhitungan Nilai Risk Priority Number (RPN).

Tabel 5. Perhitungan Nilai Risk Number Priority (RPN) Cacat Velg Rubber Roll

\begin{tabular}{|c|c|c|c|c|c|c|c|}
\hline No. & $\begin{array}{l}\text { Potential } \\
\text { Couse }\end{array}$ & Severity & Occurance & Detection & RPN & $\begin{array}{l}\text { Persentase } \\
\text { RPN (\%) }\end{array}$ & $\begin{array}{c}\text { Total } \\
\text { Persentase } \\
\text { kumulatif } \\
\text { RPN }(\%)\end{array}$ \\
\hline 1 & $\begin{array}{l}\text { Keliru dalam } \\
\text { pembuatan } \\
\text { pola dan } \\
\text { cetakan }\end{array}$ & 9 & 8 & 7 & 504 & $24,74 \%$ & $24,74 \%$ \\
\hline 2 & $\begin{array}{l}\text { Finishing } \\
\text { Melewati } \\
\text { Batas } \\
\text { Toleransi }\end{array}$ & 9 & 6 & 7 & 378 & $18,56 \%$ & $43,30 \%$ \\
\hline 3 & $\begin{array}{l}\text { Tidak Cermat } \\
\text { Dalam } \\
\text { Penuangan } \\
\text { Logam }\end{array}$ & 9 & 6 & 6 & 324 & $15,91 \%$ & $59,20 \%$ \\
\hline 4 & $\begin{array}{l}\text { Pasir cetakan } \\
\text { kurang padat }\end{array}$ & 5 & 7 & 6 & 210 & $10,31 \%$ & $69,51 \%$ \\
\hline 5 & $\begin{array}{l}\text { Pasir cetakan } \\
\text { terlalu lembab }\end{array}$ & 7 & 4 & 6 & 196 & $9,62 \%$ & $79,14 \%$ \\
\hline 6 & $\begin{array}{l}\text { Tungku } \\
\text { Peleburan } \\
\text { Tidak } \\
\text { dilakukan } \\
\text { Pembersihan } \\
\end{array}$ & 6 & 6 & 5 & 180 & $8,84 \%$ & $87,97 \%$ \\
\hline 7 & $\begin{array}{l}\text { Suhu Didih Di } \\
\text { Tungku } \\
\text { Peleburan } \\
\text { Tidak } \\
\text { dilakukan } \\
\text { Pengecekan }\end{array}$ & 7 & 5 & 5 & 175 & $8,59 \%$ & $96,56 \%$ \\
\hline 8 & $\begin{array}{l}\text { Pembongkaran } \\
\text { Terlalu Cepat }\end{array}$ & 7 & 5 & 2 & 70 & $3,44 \%$ & $100.00 \%$ \\
\hline
\end{tabular}

Dari Tabel 5, potential cause yang masuk ke dalam $80 \%$ total nilai persentase kumulatif kemudian digunakan untuk menganalisa akar penyebab masalah menggunakan metode diagram sebab akibat. 


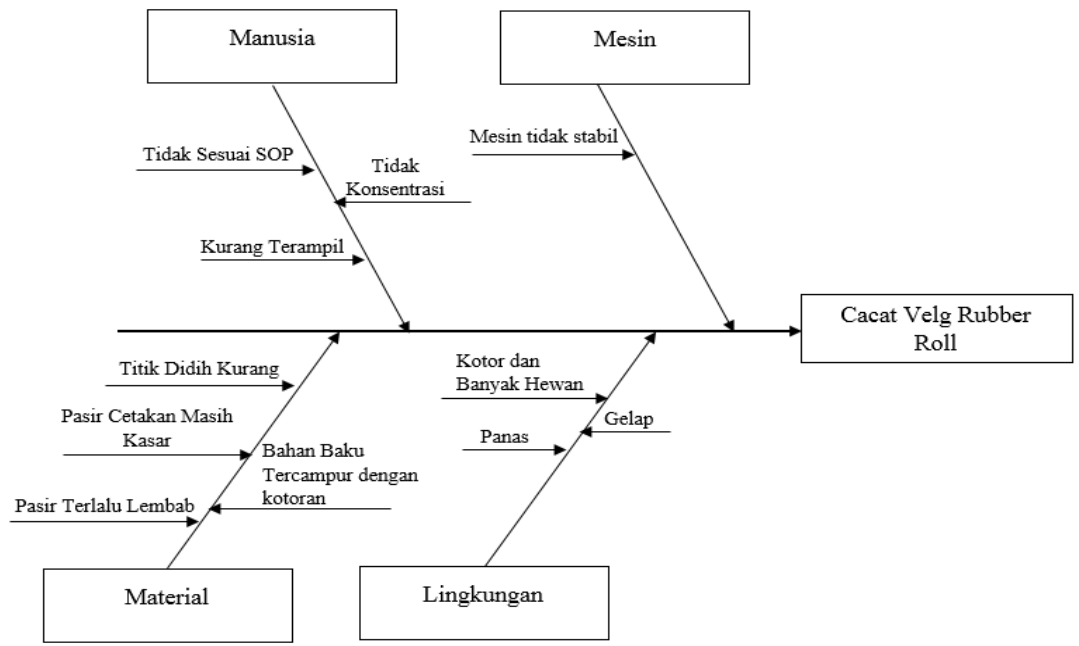

Gambar 2. Diagram sebab akibat cacat velg rubber roll

\section{Tahap Improve}

Pada tahap ini akan dilaksanakanya usulan perbaikan dari akar masalah yang terjadi agar dalam proses produksi selajutnya penyebab cacat pada proses produksi produk velg rubber roll dapat dikurangi. Upaya ini dilakukan menggunakan metode $5 \mathrm{~W}-1 \mathrm{H}$, adapun usulan perbaikan tersebut dapat dilihat pada Tabel 6.

Tabel 6. Usulan Perbaikan 5W+1H Cacat Velg Rubber Roll

\begin{tabular}{|c|c|c|c|c|c|c|c|}
\hline No & Faktor & What & Why & Where & When & Who & How \\
\hline 1 & & $\begin{array}{l}\text { Tidak sesuai } \\
\text { SOP }\end{array}$ & $\begin{array}{l}\text { Tidak adanya } \\
\text { pengawasan dan } \\
\text { teguran }\end{array}$ & $\begin{array}{l}\text { Ruang } \\
\text { pencetakan, } \\
\text { pengecoran, dan } \\
\text { peleburan }\end{array}$ & $\begin{array}{l}\text { Usulan } \\
\text { perbaikan } \\
\text { diberikan bulan } \\
\text { Agustus } 2019\end{array}$ & $\begin{array}{l}\text { Pemilik } \\
\text { pabrik atau } \\
\text { yang } \\
\text { berwenang }\end{array}$ & $\begin{array}{l}\text { Menpertegas } \\
\text { penerapan SOP } \\
\text { dan melakukan } \\
\text { pengawasan } \\
\text { secara berkala }\end{array}$ \\
\hline 2 & Manusia & $\begin{array}{l}\text { Kurang } \\
\text { konsentrasi }\end{array}$ & $\begin{array}{l}\text { Banyak } \\
\text { mengobrol pada } \\
\text { saat bekerja }\end{array}$ & $\begin{array}{l}\text { Ruang } \\
\text { pencetakan, } \\
\text { pengecoran, dan } \\
\text { peleburan }\end{array}$ & $\begin{array}{l}\text { Usulan } \\
\text { perbaikan } \\
\text { diberikan bulan } \\
\text { Agustus } 2019\end{array}$ & $\begin{array}{l}\text { Karyawan } \\
\text { bagian } \\
\text { pengecoran } \\
\text { dan } \\
\text { peleburan }\end{array}$ & $\begin{array}{l}\text { 1) Mengadakan } \\
\text { pelatihan } \\
\text { sesuai fokus } \\
\text { karyawan } \\
\text { 2) Memberikan } \\
\text { motivasi } \\
\text { kerja }\end{array}$ \\
\hline 3 & Manusia & $\begin{array}{l}\text { Kurang } \\
\text { terampil }\end{array}$ & $\begin{array}{l}\text { Operator } \\
\text { Kurang terlatih }\end{array}$ & $\begin{array}{l}\text { Area pengecoran } \\
\text { logam }\end{array}$ & $\begin{array}{l}\text { Usulan } \\
\text { perbaikan } \\
\text { diberikan bulan } \\
\text { Agustus } 2019\end{array}$ & $\begin{array}{l}\text { Manajer } \\
\text { perusahaan }\end{array}$ & $\begin{array}{l}\text { Melaksanakan } \\
\text { program } \\
\text { latihan secara } \\
\text { berkala untuk } \\
\text { operator guna } \\
\text { meningkatkan } \\
\text { skil dalam } \\
\text { bekerja }\end{array}$ \\
\hline 4 & Mesin & $\begin{array}{l}\text { Mesin tidak } \\
\text { stabil }\end{array}$ & $\begin{array}{l}\text { Kurangnya } \\
\text { perawatan }\end{array}$ & $\begin{array}{l}\text { Area peleburan } \\
\text { logam }\end{array}$ & $\begin{array}{l}\text { Usulan } \\
\text { perbaikan } \\
\text { diberikan bulan } \\
\text { Agustus } 2019\end{array}$ & $\begin{array}{l}\text { Operator } \\
\text { mesin }\end{array}$ & $\begin{array}{l}\text { Melakukan } \\
\text { perawatan } \\
\text { mesin secara } \\
\text { berkala. } \\
\text { Mengganti } \\
\text { komponen } \\
\text { mesin yang } \\
\text { telah rusak. }\end{array}$ \\
\hline
\end{tabular}


Tabel 6. Usulan Perbaikan 5W+1H Cacat Velg Rubber Roll (lanjutan)

\begin{tabular}{|c|c|c|c|c|c|c|c|}
\hline No & Faktor & What & Why & Where & When & Who & How \\
\hline 5 & Material & $\begin{array}{l}\text { Titik didih } \\
\text { kurang }\end{array}$ & $\begin{array}{l}\text { Suhu tungku } \\
\text { peleburan tidak } \\
\text { dilakukan } \\
\text { pengecekan }\end{array}$ & $\begin{array}{l}\text { Area peleburan } \\
\text { logam }\end{array}$ & $\begin{array}{l}\text { Usulan } \\
\text { perbaikan } \\
\text { diberikan } \\
\text { bulan Agustus } \\
2019\end{array}$ & $\begin{array}{l}\text { Operator } \\
\text { peleburan }\end{array}$ & $\begin{array}{l}\text { Suhu tungku } \\
\text { peleburan dilakukan } \\
\text { pengecekn sebelum } \\
\text { logam dipindahkan } \\
\text { ke ladel besar }\end{array}$ \\
\hline 6 & & $\begin{array}{l}\text { Pasir cetakan } \\
\text { masih kasar }\end{array}$ & $\begin{array}{l}\text { Pasir tidak } \\
\text { dicek } \\
\text { kehaluasanya }\end{array}$ & $\begin{array}{l}\text { Area percetakan } \\
\text { atau pengecoran }\end{array}$ & $\begin{array}{l}\text { Usulan } \\
\text { perbaikan } \\
\text { diberikan } \\
\text { bulan Agustus } \\
2019\end{array}$ & $\begin{array}{l}\text { Operator } \\
\text { percetakan } \\
\text { atau } \\
\text { pengecoran }\end{array}$ & $\begin{array}{l}\text { Pasir disaring } \\
\text { terlebih dahulu } \\
\text { sebelum digunakan }\end{array}$ \\
\hline 7 & & $\begin{array}{l}\text { Pasir cetakan } \\
\text { terlalu lembab }\end{array}$ & $\begin{array}{l}\text { Pasir yang } \\
\text { digunakan } \\
\text { merupakan } \\
\text { pasir baru }\end{array}$ & $\begin{array}{l}\text { Ruang mixing } \\
\text { pasir }\end{array}$ & $\begin{array}{l}\text { Usulan } \\
\text { perbaikan } \\
\text { diberikan } \\
\text { bulan Agustus } \\
2019\end{array}$ & $\begin{array}{l}\text { Karyawan } \\
\text { bagian } \\
\text { mixing } \\
\text { pasir }\end{array}$ & $\begin{array}{l}\text { 1) Memeriksa } \\
\text { kondisi pasir } \\
\text { yang akan } \\
\text { digunakan, } \\
\text { terutama } \\
\text { perbedaan kadar } \\
\text { air antara pasir } \\
\text { lama dengan } \\
\text { pasir baru, agar } \\
\text { supaya } \\
\text { disamakan } \\
\text { kondisinya }\end{array}$ \\
\hline 8 & Material & $\begin{array}{l}\text { Bahan baku } \\
\text { tercampur } \\
\text { kotoran }\end{array}$ & $\begin{array}{l}\text { Kurang teliti } \\
\text { dalam } \\
\text { pembersihan } \\
\text { terak }\end{array}$ & $\begin{array}{l}\text { Area peleburan } \\
\text { logam }\end{array}$ & $\begin{array}{l}\text { Usulan } \\
\text { perbaikan } \\
\text { diberikan } \\
\text { bulan Agustus } \\
2019\end{array}$ & $\begin{array}{l}\text { Operator } \\
\text { peleburan } \\
\text { Logam }\end{array}$ & $\begin{array}{l}\text { 1) Penambahan } \\
\text { selek remover } \\
\text { untuk } \\
\text { membersihkan } \\
\text { terak harus } \\
\text { dilakukan } \\
\text { berkali-kali } \\
\text { 2) Pembersihan } \\
\text { rarus teliti agar } \\
\text { kotoran/terak } \\
\text { hilang } \\
\text { sepenuhnya }\end{array}$ \\
\hline 9 & Lingkungan & $\begin{array}{l}\text { Kotor dan } \\
\text { banyak hewan } \\
\text { kecil }\end{array}$ & $\begin{array}{l}\text { Jarang } \\
\text { dilakukan } \\
\text { pembersihan } \\
\text { area kerja }\end{array}$ & $\begin{array}{l}\text { Area pencetakan } \\
\text { atau pengecoran }\end{array}$ & $\begin{array}{l}\text { Usulan } \\
\text { perbaikan } \\
\text { diberikan } \\
\text { bulan Agustus } \\
2019\end{array}$ & $\begin{array}{l}\text { operator } \\
\text { bagian } \\
\text { pencetakan } \\
\text { atau } \\
\text { pengecoran }\end{array}$ & 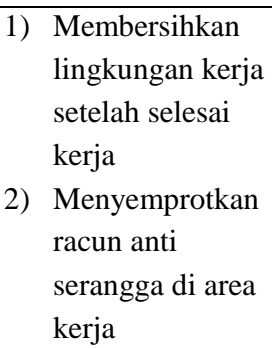 \\
\hline
\end{tabular}


Tabel 6. Usulan Perbaikan 5W+1H Cacat Velg Rubber Roll (lanjutan)

\begin{tabular}{|c|c|c|c|c|c|c|c|}
\hline No & Faktor & What & Why & Where & When & Who & How \\
\hline 10 & & Gelap & $\begin{array}{l}\text { Kurangnya } \\
\text { alat } \\
\text { penerangan }\end{array}$ & $\begin{array}{l}\text { Area } \\
\text { pencetakan } \\
\text { atau } \\
\text { pengecoran }\end{array}$ & $\begin{array}{l}\text { Usulan } \\
\text { perbaikan } \\
\text { diberikan } \\
\text { bulan } \\
\text { Agustus } \\
2019\end{array}$ & $\begin{array}{c}\text { Manajer } \\
\text { perusahaan }\end{array}$ & $\begin{array}{c}\text { Melakukan } \\
\text { penambahan } \\
\text { fasilitas seperti } \\
\text { lampu di sudut- } \\
\text { sudut tertentu di } \\
\text { area pengecoran } \\
\text { logam }\end{array}$ \\
\hline 11 & & Panas & $\begin{array}{ll}\text { 1) } & \text { Atap } \\
\text { yang } \\
\text { terbuat } \\
\text { dari seng } \\
\text { 2) } & \text { Sirkulasi } \\
& \text { udara } \\
& \text { yang } \\
& \text { kurang } \\
\text { 3) } & \text { Lokasi } \\
& \text { Dekat } \\
& \text { dengan } \\
& \text { tungku } \\
& \text { peleburan }\end{array}$ & $\begin{array}{l}\text { Area } \\
\text { pencetakan } \\
\text { dan } \\
\text { pengecoran }\end{array}$ & $\begin{array}{l}\text { Usulan } \\
\text { perbaikan } \\
\text { diberikan } \\
\text { bulan } \\
\text { Agustus } \\
2019\end{array}$ & $\begin{array}{l}\text { Manajer } \\
\text { perusahaan }\end{array}$ & $\begin{array}{l}\text { 1) Menambahka } \\
\mathrm{n} \text { Blower atau } \\
\text { ventilasi } \\
\text { untuk } \\
\text { memperbaiki } \\
\text { sirkulasi udara } \\
\text { 2) Lokasi } \\
\text { pengecoran } \\
\text { agak bergeser } \\
\text { menjaauhi } \\
\text { tungku } \\
\text { peleburan } \\
\text { 3) Melapisi atap } \\
\text { dengan foam } \\
\text { agar tidak } \\
\text { terlalu panas }\end{array}$ \\
\hline
\end{tabular}

\section{Tahap control}

Penelitian ini hanya sampai pada tahap rekomendasi, tidak sampai sampai pada tahap implementasi dan pengendalian sehingga tidak bisa dilanjutkan pada tahap control.

\section{SIMPULAN}

Berdasarkan Penelitian Yang telah dilakukan di PT.XYZ dapat ditarik kesimpulan sebagai berikut:

1. Jenis cacat produk velg rubber roll di PT.XYZ adalah cacat mengsle (kondisi produk tidak simetris atau ukuran sisi produk tidak rata dan sama), cacat lepot (kondisi besi kurang mengisi bagian cetakan, kemudian mengakibatkan terjadinya cekungan-cekungan pada produk) dan cacat kropos (kondisi terdapat banyaknya udara yang terperangkap didalam besi cor dan menghasilkan besi cor yang tidak kokoh).

2. Faktor penyebab cacat pada velg rubber roll yaitu: keliru dalam pembuatan pola dan cetakan, finishing melewati batas toleransi, tidak cermat dalam penuangan logam, pasir cetakan kurang padat, pasir cetakan terlalu lembab dan tungku peleburan tidak dilakukan pembersihan

3. Usulan perbaikan yang diberikan kepada pihak perusahaan untuk mengurangi jumlah cacat dalam proses produksi yaitu: Melakukan pelatihan kerja bagi para operator, melakukan penilaian kinerja dan melakukan pengawasan pada setiap aktivitas kerja operator. Melakukan pemeliharaan mesin secara berkala, melakukan inspeksi pasir cetakan, bahan baku dan uji spesifikasi bahan baku.Menambah lampu penerangan serta ventilasi udara.

\section{DAFTAR PUSTAKA}

[1] Tannady, Hendi. (2015). Pengendalian Kualitas. Yogyakarta: Graha Ilmu

[2] Gasperz, Vincent. (2001). Total Quality Management.Jakarta: PT.Gramedia Pustaka Utama.

[3] Wahyuni, Hana Catur., Sulistiyowati, Wiwik., Khamim, Muhammad. (2015). Pengendalian Kualitas. 
Yogyakarta: Graha Ilmu.

[4] Pande, Peter S., Neuman, Robert P., Roland R. (2000). The Six Sigma Way, McGraw Hill, New York.

[5] Soemohadiwidjojo, Arini T. (2017). Six Sigma "Metode Pengukuran Kinerja Perusahaan Berbasis Statistik". Jakarta: Raih Asa Sukses.

[6] Tjiptono, F \& Diana, A. (2003). Total Quality Management, Edisi Revisi. Yogyakarta: Andi. 